\title{
AIRCRAFT POSITION PREDICTION DURING THE CROSSWIND APPROACH
}

\author{
Marek Grzegorzewski**, Jerzy Biały \\ Institute of Navigation, Military University of Aviation, Deblin, Poland \\ *E-mail of corresponding author: m.grzegorzewski@law.mil.pl
}

\section{Resume}

Testing the impact of the drag coefficient on an F16 aircraft model, depending on the angle of attack $\alpha$ was performed. First, a navigation model was introduced describing the preliminary and computational assumptions of the model. The final part of the present paper contains the relationships between the wind angle and the wind correction angle at the angle of attack $\alpha=0^{0}, \alpha=11^{0}, \alpha=13^{0}$ for a full-scale F-16 aircraft. The tables present results of all the calculations for individual angles of attack, taking into account variable wind angles relative to the longitudinal axis of the runway. The values show the corrections calculated for an 1/19 scale aircraft model and for a full-scale F16 aircraft. The "right" and "left" designations represent the direction from which the wind blows in relation to the aircraft.

\section{Article info}

Received 16 March 2021

Accepted 19 April 2021

Online 8 November 2021

\section{Keywords:}

GPS, position prediction, navigation

\section{Introduction}

Accurate determination of the aircraft's position has always been one of the fundamental reasons for existence of the air navigation. This allows pilots to perform air operations safely and accurately. Landing is the most crucial moment of every flight. That is the phase which is the most burdensome for pilots, requiring the high degree of commitment and focus. Prediction of the aircraft's position during the landing approach may be used in order to reduce the pressure placed on pilots at that time. Accurate information provided to the pilot, concerning their current position, allows for more accurate and, what is important, the safer operations. In order to develop a method for the position prediction, experimental studies of aerodynamic characteristics were used, which were performed in the wind tunnel with a measurement space diameter $\varnothing=1.1 \mathrm{~m}$, which belongs to the Military University of Technology, Warsaw Poland. The model used for determination of all the characteristics was an 1/19 scale F-16, which, at that time, had a closed engine inlet channel and an exhaust cone with asymmetric air flow. All the calculations and findings of the above work refer to the above-mentioned model in a "clean" configuration, i.e. all the control surfaces, high-lift devices and aerodynamic brakes are not deflected and the landing gear is retracted. Tests were performed for asymmetric flow at sideslip angles of up to $\beta=-30^{0}$ to $30^{\circ}$ at every $2^{0}$ for angle of attack, $\alpha=0^{0}, \alpha=11^{0}, \alpha=13^{0}$, which, according to the Flight Manual, correspond to the angles occurring during the landing approach. The measurements were conducted under the following conditions: velocity pressure $q=1000[\mathrm{~Pa}]$ $\left(\mathrm{V} \approx 40\left[\mathrm{~m} \cdot \mathrm{s}^{-1}\right]\right)$, Reynolds number $\operatorname{Re} \approx 4.5 \times 10^{5}$. The test results were prepared in the form of graphs showing the courses of the drag coefficient as a function of the sideslip angle $\beta$, with a fixed angle of attack $\alpha=\mathrm{C}_{x a}=\mathrm{f}$ ( $\beta, \alpha=$ const) [1].

\section{Materials and methods}

The objective of the calculations performed in the present work was to make it easier for the pilot to keep the aircraft aligned with the axis of the runway during the crosswind approach. The impact of a crosswind on the aircraft may be crucial during the precision approaches. Strong wind at a high angle in relation to the runway axis can prevent safe operation of even the heaviest and most powerful flying machines. The aim of the following calculations was to show how it acts on an aircraft during the most critical flight phase - landing.

\subsection{Calculation assumptions}

The first calculations concern a 1/19 scale model of an F-16 aircraft, as it was described in the introduction [2]. One of the basic assumptions is that the calculations were performed for the short periods of time and, 


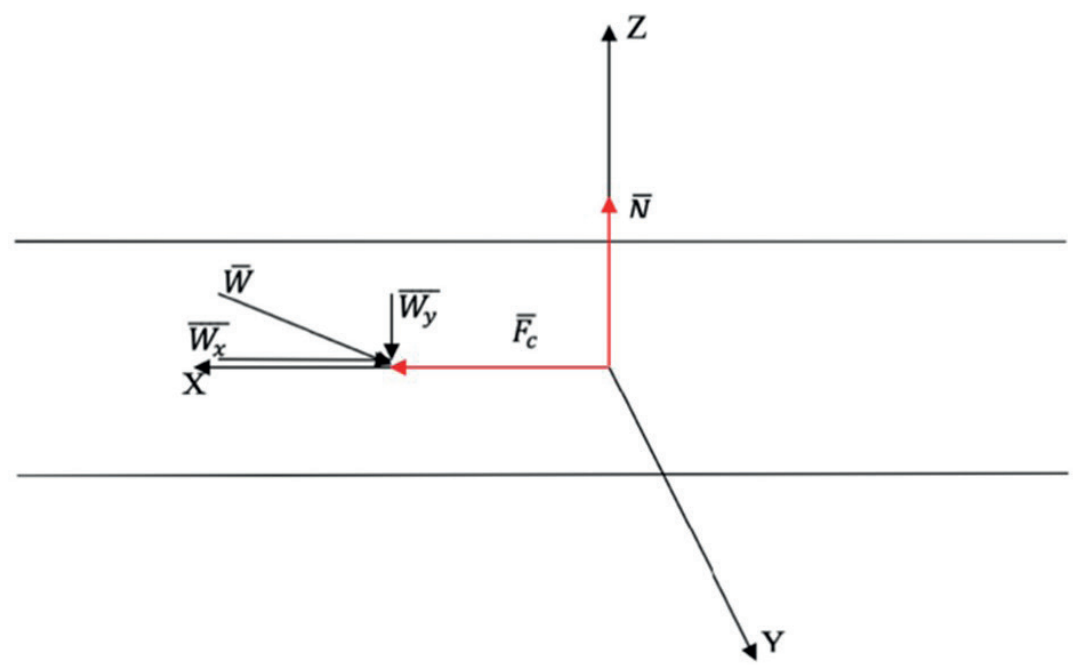

Figure 1 Presentation of trigonometric relationships for the F-16 model at the angle of attack $a=0^{\circ}$ and wind angle $5^{0,}$ where: $\bar{F}_{c}$ - thrust, $\bar{N}$ - lift

consequently, it can be assumed that the wind speed and direction do not change their values in relation to those assumed. The above-mentioned values are, among others, wind speed, which remains constant $\mathrm{V}_{w}=40 \mathrm{~m} \cdot \mathrm{s}^{-1}$, and its direction, the angle of which with respect to the runway axis was $5^{0}, 10^{\circ}$ and $15^{\circ}$, both to the left and to the right. Moreover, the wind direction was parallel to the runway and the wind neither blew onto the aircraft from below nor from above. The model of the aircraft during the tunnel tests was set under three angles of attack values in relation to the air flow: $\alpha=0^{0}, \alpha=11^{0}$ and $\alpha=13^{\circ}$, which were also taken into consideration in the calculations. The approach speeds of the F-16 aircraft are closely related to the angle of attack, which varies depending on the angle $\alpha$ selected. For $\alpha=0^{0}$, the approach speed is 152 knots (IAS - Indicated Airspeed), for $\alpha=11^{0},-144$ knots (IAS) and for $\alpha=13^{\circ},-136$ knots (IAS) [3]. Moreover, along with the approach speeds of the aircraft, there is also a change of its allowable mass at which the aircraft would retain the appropriate handling characteristics: $\mathrm{V}=152$ kt - $25000 \mathrm{lbs}, \mathrm{V}=144 \mathrm{kt}-22500 \mathrm{lbs}, \mathrm{V}=136 \mathrm{kt}-20000$ lbs [4]. In order to maintain the stability of the glide slope, the engines must generate adequate thrust to keep the speed within a safe range. Turbofan augmented engine, F110-GE-129, is a standard propulsion system used in F-16 aircraft. It is capable of generating $70 \mathrm{kN}$ of thrust without and $131 \mathrm{kN}$ with afterburning. When analyzing the graphs contained in the manual, one can formulate the following assumption: with the maximum thrust, without afterburning equal to $70 \mathrm{kN}$, the $\mathrm{F}-16$ aircraft engine is able to accelerate to a maximum speed of $660 \mathrm{kt}$. Owing to this assumption, it would be possible to determine the thrust needed during the approach, depending on the approach speed required. Furthermore, an additional assumption facilitating the determination of the thrust, would be making the approach speed dependent on specific masses. Researchers conducting tunnel tests assumed the velocity pressure $q=1000[\mathrm{~Pa}]$ and found the area of the model surface $S=0.0698\left[\mathrm{~m}^{2}\right]$. These are the data that, together with $\mathrm{C}_{x}$ coefficients, proportional to the respective angles of attack and sideslip would make it possible to calculate the slip forces acting on the F-16 aircraft using the formulas:

$q=\frac{\rho V^{2}}{2}, P_{x}=q \cdot S \cdot C_{x}$

where:

$q$ - velocity pressure (dynamic),

$\rho$ - air density,

$V$ - velocity of the body,

$P_{x}$ - slip force (drag),

$S$ - model area,

$C_{x}$ - drag coefficient.

However, before calculating the aircraft's slip forces, its exact speed relative to the air flow ought to be calculated. To that end, the trigonometric relationships between vectors must be used.

The situation of the first instance, i.e. the angle of attack being $\alpha=0^{\circ}$, and the angle between the wind and the runway axis being $5^{0}$ was shown in Figure 1.

This illustration shows the location of the major X, $\mathrm{Y}$ and $\mathrm{Z}$ axes and the vectors of the slip forces acting on the aircraft. Thrust $\bar{F}_{c}$ acts on the aircraft along its longitudinal axis $\mathrm{X}$, lift $\bar{N}$ acts along the vertical axis $\mathrm{Z}$ and the $\mathrm{Y}$ axis is the transverse (pitch) axis of the aircraft. The vector $W_{x}$ is the vector of the slip force of the wind blowing straight against the nose of the aircraft, while $W_{y}$ is the vector of the slip force of wind blowing sideways against the side of the aircraft at an angle of $90^{\circ}$. $\bar{W}$ vector is the resultant vector of the two vectors, $W_{x}$ and $W_{y}$, which allows to determine the influence of the crosswind depending on its angle in relation to the longitudinal runway axis. Moreover, the exact values of thrust that are required for calculation of the relevant corrections should be determined. To this end, having 
the previously given values of $F_{c}=70 \mathrm{kN}$ and $\mathrm{V}=660$ kt, the values $F_{c}$, required for specific speeds, may be determined based on the following proportions:

For $\mathrm{V}=152 \mathrm{kts} ; 70000 \mathrm{~N}-660 \mathrm{kts}$

$\mathrm{x}-152 \mathrm{kts}$

$\mathrm{x}=\frac{70000 \mathrm{~N} \cdot 152 \mathrm{kts}}{660 \mathrm{kts}}=16121.21 \mathrm{~N}$

For V $=144$ kts; $70000 \mathrm{~N}-660 \mathrm{kts}$ $\mathrm{x}-144 \mathrm{kts}$

Owing to the thrust values, calculated for an actual F-16 aircraft, in the calculations concerning the aircraft model, it would be possible to determine the thrust force proportional to the surface and mass of the $1 / 19$ scale model.

\subsection{Calculations of the slip forces acting on the 1/19 scale F-16 model [5]}

Trigonometric formulas ought to be used in order to calculate the component vectors $\mathrm{W}_{x}$ and $\mathrm{W}_{y}$. The resultant $\mathrm{W}$ may be determined by applying the difference of cosines for $90^{\circ}$ angles and for the first situation examined $5^{0}$. Furthermore, values obtained from calculation of cosines should be multiplied by the speed of the wind blowing at a given moment. In this case it is $V_{w}=40 \mathrm{~m} \cdot \mathrm{s}^{-1}$. Applying the above instructions, one obtains:

$40\left[\mathrm{~m} \cdot \mathrm{s}^{-1}\right] \cos 90^{0}-\left(40\left[\mathrm{~m} \cdot \mathrm{s}^{-1}\right] \cos 5^{0)}=0-39.85=39.85\right.$.

The solution of the above problem should then be subtracted, in accordance with the sign in front of the numerical value, from the speed of the aircraft depending on the given angle of attack $\alpha$. In this case, for the first example the speed was 152 knots, which corresponds to the angle of $\alpha=0^{0}$.

To begin with, it is necessary to convert the unit of 152 knots into the same unit as specified for the wind speed, i.e. meters per second. Using the calculation formulas below, one obtains:

$\mathrm{V}[\mathrm{kt}] \cdot 1.852=$

$\mathrm{V}\left[\mathrm{km} \cdot \mathrm{h}^{-1}\right] \alpha \rightarrow \mathrm{V}\left[\mathrm{km} \cdot \mathrm{h}^{-1}\right] \cdot 3.6=\mathrm{V}\left[\mathrm{km} \cdot \mathrm{h}^{-1}\right]$

$152[\mathrm{kts}] \cdot 1.852=281.5\left[\mathrm{~km} \cdot \mathrm{h}^{-1}\right] \rightarrow$

$\rightarrow 281.5\left[\mathrm{~km} \cdot \mathrm{h}^{-1}\right] \div 3.6=78.20\left[\mathrm{~m} \cdot \mathrm{s}^{-1}\right]$.

Having an exactly calculated speed value relative to the air flow, one can calculate the value of the speed over the ground, referred to as ground speed (GS), according to the formula:

$$
\begin{aligned}
& \mathrm{GS}=78.20\left[\mathrm{~m} \cdot \mathrm{s}^{-1}\right]-39.85\left[\mathrm{~m} \cdot \mathrm{s}^{-1}\right]= \\
& =38.35\left[\mathrm{~m} \cdot \mathrm{s}^{-1}\right] .
\end{aligned}
$$

After determining the GS, the mass and thrust of the F-16 model should be determined in relation to an actual aircraft [6]. In order to do that, the proportions should be used. To calculate the mass of the model, the surface area, the mass of the aircraft and the surface area of the model should be combined with one another, as follows:

$$
\begin{aligned}
& 25000 \mathrm{lbs} \cdot 0.4536=11340 \mathrm{~kg} \\
& 27.87 \mathrm{~m}^{2}-0.0698 \mathrm{~m}^{2} \\
& 11340 \mathrm{~kg}-\mathrm{x} \\
& \mathrm{x}=\frac{11340 \cdot 0.0698 \mathrm{~m}^{2}}{27.87 \mathrm{~m}^{2}}=28.40 \mathrm{~kg}
\end{aligned}
$$

where: $27.87 \mathrm{~m}^{2}$ - surface area of the real F16 aircraft, $0.0698 \mathrm{~m}^{2}$ - surface area of the 1/19 aircraft model,

$11340 \mathrm{~kg}$ - mass of the full-scale F-16 at velocity $\mathrm{V}=78.20 \mathrm{~m} \cdot \mathrm{s}^{-1}$

The calculated mass is a computational assumption necessary in the subsequent action to determine the approximate thrust for a model, proportional to that required for an actual aircraft. This is done by using the basic formula for thrust:

$\mathrm{F}_{c}=\mathrm{m} \cdot \mathrm{a}$.

Having the thrust of an actual F-16 for a given V at a given mass, the value of its acceleration is to be determined for the given conditions:

$16121.21 \mathrm{~N}=11340 \mathrm{~kg} \cdot \mathrm{a}$, $\mathrm{a}=\frac{16121.21 \mathrm{~N}}{11340 \mathrm{~kg}}=1.42 \mathrm{~m} . \mathrm{s}^{-2}$.

Then, knowing that the acceleration in the case under consideration is to be the same, one can determine the approximate thrust of the model:

$\mathrm{F}_{\mathrm{c}}=28.40 \mathrm{~kg} \cdot 1.42 \mathrm{~m} . \mathrm{s}^{-2}=40.33 \mathrm{~N}$.

After solving the above problems, calculations of the slip force $P_{x}$ should be commenced. In order to do that, the formula for force should be used which was presented in the previous subsection. The following values were used in the calculations given below: dynamic pressure $q$ $=1000[\mathrm{~Pa}]$, surface area of the model tested $\mathrm{S}=0.0698$ $\mathrm{m}^{2}$ and the drag coefficient values $\mathrm{C}_{x}$ from Table 1 for wind blowing from the right -0.02931 and from the left 0.02945 at the angle of attack $\alpha=0^{\circ}$. Having calculated values of thrust $F_{c}$ and slip force $P_{x}$, it is possible to determine the value of the angular correction to be used by the pilot in order to continue the straight flight, undisturbed by the crosswind impact. For this purpose, the next trigonometric formula has to be used, this time for the tangent of an angle.

$\mathrm{P}_{x}=\left[P_{a}\right] \cdot 0.0698\left[\mathrm{~m}^{2}\right] \cdot 0.02931=2.05[\mathrm{~N}]$.

Figure 2 presents the mutual orientation of thrust 
Thrust $F_{c}=40.33 \mathrm{~N}$

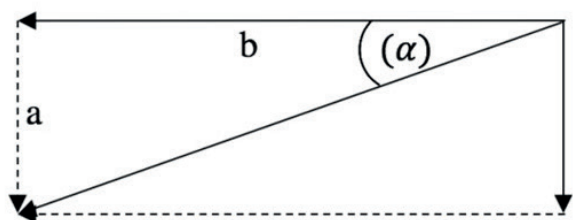

Slip force $P_{x}=2.05 \mathrm{~N}$

$\mathrm{N} 38.35[\mathrm{mls}]$

Figure 2 Presentation of the dependence of thrust and slip force vectors with the wind blowing at $5^{\circ}$ from the right and the angle of attack $\alpha=0^{0}$

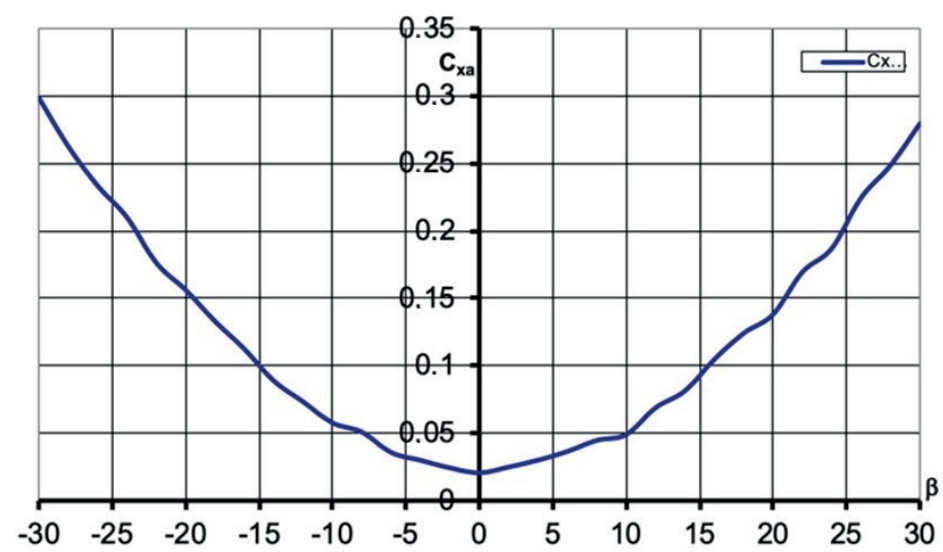

Figure 3 Drag coefficient graph of the F-16 model as a sideslip angle function for the angle of attack $a=0^{\circ}$

and slip force vectors. A resultant vector was drawn between them, which designates two triangles sharing an edge. In order to calculate a correction, required to correct the aircraft flight path, one should first determine the value of the angle tangent $\alpha$ and then convert it to an angular value indicating by how many degrees the aircraft should yaw.

Following the above guidelines, one obtains:

$\tan \alpha=\frac{a}{b} \rightarrow \tan \alpha=\frac{2.05[N]}{40.33[N]}=0.0508 \rightarrow 2.09^{\circ}$.

Using a calculator converting the value of a tangent function into an angular value, one can obtain the value of $2.90^{\circ}$, which in this case means that in order to correct the crosswind impact, the pilot, must deflect the plane by the angle given against the wind, i.e. to the right. The same principle applies to the wind blowing from the left. The only change in the calculations would be a different value of the $C_{x}$ coefficient.

\section{Results}

\subsection{Analysis of the drag coefficient influence on the F-16 aircraft model depending on the angle of attack $\alpha[4]$}

\subsubsection{Drag coefficient as a function of the sideslip angle for angle of attack $\alpha=0^{0}$}

The curve of a drag coefficient $C_{x a}$ as a function of the sideslip angle is parabolic. The minimum value of the drag coefficient may be observed for the sideslip angle $\beta \approx 0^{0}$ and its value is then $C_{\text {xamin }}=0.02004$ (Figure 3 ). In the sideslip angle range from $\beta \approx-15^{0}$ to $\beta \approx 16^{0}$, the drag coefficient does not exceed 0.1. For sideslip angles greater than the above, the intensity of increase of $C_{x a}$ grows, achieving at $\beta \approx-30^{\circ}$ the value of $C_{x a}=0.29896$, whereas at $\beta \approx 30^{\circ}$ to $C_{x a}=0.27966$.

\subsubsection{Drag coefficient as a function of sideslip angle for the angle of attack $\alpha=1^{0}$}

It can be observed that the shape of the characteristics $\mathrm{C}_{x \alpha}=\mathrm{f}(\beta)$ is parabolic in this case, as well. Here, however, there are significant differences in its course (Figure 4). The minimum drag coefficient $\mathrm{C}_{\text {xamin }}=0.16449$ is achieved at the sideslip angle $\beta \approx 4^{0}$. In the sideslip angle range from $\beta \approx-20$ to $\beta \approx 21 \mathrm{drag}$ coefficient does not exceed 0.3. At the sideslip angles defining the boundaries of the graph, the coefficient $\mathrm{C}_{x a}$ starts increasing much faster, which results in the fact that, for $\beta \approx-30^{\circ}$, the drag coefficient reaches $\mathrm{C}_{x a}$ $=0.43481$ whereas at $\beta \approx 30^{\circ}$, reaches the value $\mathrm{C}_{x a}=$ 0.41274 .

Another factor, which has an additional influence on the increase of the drag coefficient, is the value of the sideslip angle. In such a situation, as in the angle of attack change mentioned above, any deviation from the axis of the air flow causes an increase in drag. However, in this case the motion occurs in relation to the vertical axis ( $\mathrm{Z}$ axis) of the aircraft. When 


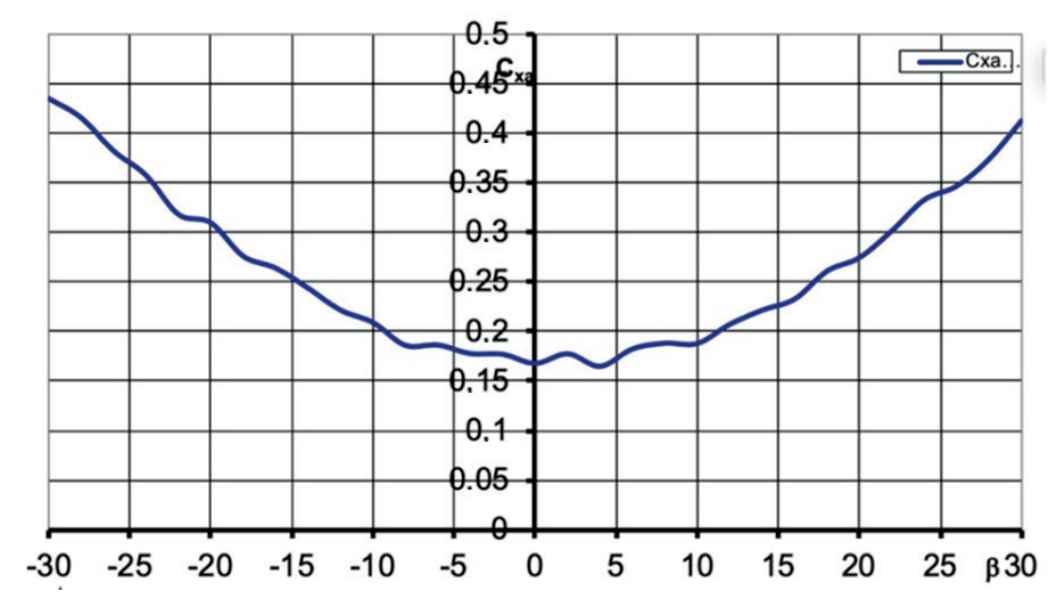

Figure 4 Drag coefficient graph of the F-16 model as a sideslip angle function for the angle of attack $\alpha=11^{0}$

Table 1 Results of the correction angle calculations for the F16 model in 1/ 19 scale

\begin{tabular}{|c|c|c|c|c|c|}
\hline \multicolumn{6}{|c|}{$\alpha={ }^{0} \mathrm{~V}=152 \mathrm{kt} / 78.20\left[\mathrm{~m} . \mathrm{s}^{-1}\right]$} \\
\hline \multicolumn{2}{|c|}{$5^{0}$} & \multicolumn{2}{|c|}{$10^{\circ}$} & \multicolumn{2}{|c|}{$15^{0}$} \\
\hline Left & Right & Left & Right & Left & Right \\
\hline$-2.92^{0}$ & $2.90^{\circ}$ & $-4.79^{0}$ & $5.65^{0}$ & $-10.26^{0}$ & $10.98^{0}$ \\
\hline \multicolumn{6}{|c|}{$\alpha=11^{0} \mathrm{~V}=144 \mathrm{kt} / 74.08\left[\mathrm{~m} . \mathrm{s}^{-1}\right]$} \\
\hline \multicolumn{2}{|c|}{$5^{0}$} & \multicolumn{2}{|c|}{$10^{0}$} & \multicolumn{2}{|c|}{$15^{0}$} \\
\hline Left & Right & Left & Right & Left & Right \\
\hline$-16.65^{0}$ & $17.90^{\circ}$ & $-18.83^{\circ}$ & $20.81^{0}$ & $-22.93^{0}$ & $-25.64^{0}$ \\
\hline \multicolumn{6}{|c|}{$\alpha=13^{0} \mathrm{~V}=136 \mathrm{kt} / 69.96\left[\mathrm{~m} \cdot \mathrm{s}^{-1}\right]$} \\
\hline \multicolumn{2}{|c|}{$5^{0}$} & \multicolumn{2}{|c|}{$10^{0}$} & \multicolumn{2}{|c|}{$15^{0}$} \\
\hline Left & Right & Left & Right & Left & Right \\
\hline$-23.32^{0}$ & $24.42^{0}$ & $-26.10^{0}$ & $26.52^{0}$ & $-29.12^{0}$ & $31.51^{0}$ \\
\hline
\end{tabular}

Table 2 Results of the correction angle calculations for the full scale F16

\begin{tabular}{|c|c|c|c|c|c|}
\hline \multicolumn{6}{|c|}{$\alpha=0^{0} \mathrm{~V}=152 \mathrm{kt} / 78.20\left[\frac{\mathrm{m}}{\mathrm{s}}\right]$} \\
\hline \multicolumn{2}{|c|}{$5^{0}$} & \multicolumn{2}{|c|}{$10^{0}$} & \multicolumn{2}{|c|}{$15^{0}$} \\
\hline Left & Right & Left & Right & Left & Right \\
\hline$-2.92^{0}$ & $2.86^{0}$ & $-4.80^{\circ}$ & $5.65^{0}$ & $-10.20^{\circ}$ & $10.98^{\circ}$ \\
\hline \multicolumn{6}{|c|}{$\alpha=11^{0} \mathrm{~V}=144 \mathrm{kt} / 74.08\left[\frac{\mathrm{m}}{\mathrm{s}}\right]$} \\
\hline \multicolumn{2}{|c|}{$5^{0}$} & \multicolumn{2}{|c|}{$10^{0}$} & \multicolumn{2}{|c|}{$15^{0}$} \\
\hline Left & Right & Left & Right & Left & Right \\
\hline$-16.70^{\circ}$ & $17.95^{0}$ & $-18.88^{0}$ & $20.86^{0}$ & $-22.98^{0}$ & $25.69^{\circ}$ \\
\hline \multicolumn{6}{|c|}{$\alpha=13^{0} \mathrm{~V}=136 \mathrm{kt} / 69.96\left[\frac{\mathrm{m}}{\mathrm{s}}\right]$} \\
\hline \multicolumn{2}{|c|}{$5^{0}$} & \multicolumn{2}{|c|}{$10^{0}$} & \multicolumn{2}{|c|}{$15^{0}$} \\
\hline Left & Right & Left & Right & Left & Right \\
\hline$-23.32^{0}$ & $24.42^{0}$ & $-26.11^{0}$ & $26.52^{0}$ & $-29.12^{0}$ & $31.51^{0}$ \\
\hline
\end{tabular}

comparing the above two graphs to each other, one can come to yet another conclusion, which is related to the difference between the minimum and maximum value of the drag coefficient, relative to the angle of attack and the sideslip angle. By analyzing the graph for the zero-degree angle of attack, it can be noticed that, in comparison to the rest of the graphs, it has the largest difference between the minimum and the maximum value of the drag coefficient. This points to the fact that sideslips of an F-16 plane in straight and level flight at a zero-degree angle of attack are much more harmful to the aircraft characteristics than at $11^{0}$ angles. 


\section{Discussion}

Tables 1 and 2 present results of all the calculations for individual angles of attack, taking into account variable wind angles relative to the longitudinal axis of the runway. The values show the corrections, calculated for an 1/19 scale aircraft model and for a full-scale F16 aircraft. The "right" and "left" designations represent the direction from which the wind blows in relation to the aircraft. The values above them, i.e. $5^{0}, 10^{0}, 15^{0}$ are its angles.

When analyzing the results for the angle of attack $\alpha=0^{0}$, one may notice that the discrepancy between the results for the model and the actual aircraft is not large. This points out to the fact that all the calculation assumptions were formulated correctly. Owing to that, the values are very similar to one another, the differences are slight and they should not significantly affect the precision and safety of the approach. Such accuracy of the results also shows that the 1/19 model aircraft has been tested correctly and that it is a real model of an actual aircraft. Particularly worth noting are the corresponding values of drag forces $P_{x}$ calculated in the above work and those presented by the Military University of Technology, Warsaw Poland. The largest difference between the results obtained may be seen between the corrections for the wind blowing at $15^{0}$ from the left, for the angle of attack $\alpha=0^{0}$. In that case the difference was $0.06^{0}$; as mentioned before, its value is small and it has no significant effect on conducting the operation. A lot of calculation results were congruent with one another. In sixteen, out of thirty-six calculations performed, exactly the same value was obtained, which shows the validity of computational assumptions and the fact that the model simulated the behavior of an actual F-16 in crosswind very precisely. It may be observed, in the results obtained, that the most rapid change between the correction values takes place where the biggest difference in the angles of attack occurred, i.e. between $\alpha=0^{\circ}$ and $\alpha=11^{\circ}$. In this situation, the arithmetic mean of differences (mean difference) of the corrections for the model is $14.2^{0}$, whereas for the actual F-16 it is $-14.28^{0}$

Comparing this to discrepancies in the change from $\alpha=11^{0}$ to $\alpha=13^{0}$, where the arithmetic mean of differences (mean difference) of the corrections for the model was $6.37^{\circ}$ and $-6.32^{\circ}$ for the actual F-16, one may see that there was almost a two-fold increase in the value of the corrections. It is worth noting that with the angle of attack increase by $11^{\circ}$ the increase of corrections is significantly lower than when the angle of attack increased by $2^{\circ}$ between $\alpha=11^{0}$ and $\alpha=13^{\circ}$. As shown previously, taking into account, e.g. the aircraft model at the increase of $\alpha=0^{0}-11^{0}$ the value is $14.21^{0}$, whereas for the increase of $\alpha=11^{0}$ to $13^{0}$ it was $6.37^{\circ}$. This shows that the F-16 aircraft is very sensitive to crosswind at higher angles of attack. The result of this observation may also be influenced by the fact that for the angles of attack being $\alpha=11^{0}, \alpha=13^{0}$ the aircraft was flying at lower speeds, which could also have affected its inferior crosswind resistance.

Graphs presented in Figures 5 and 6 show the corrections, which were obtained from calculations. Due to the fact that the values obtained do not differ significantly from each other, it can be observed that the course of both charts is almost identical. The only difference between them is the slightly steeper course of the graph in the $(-4.79)-(-10.26)$ range for the F-16

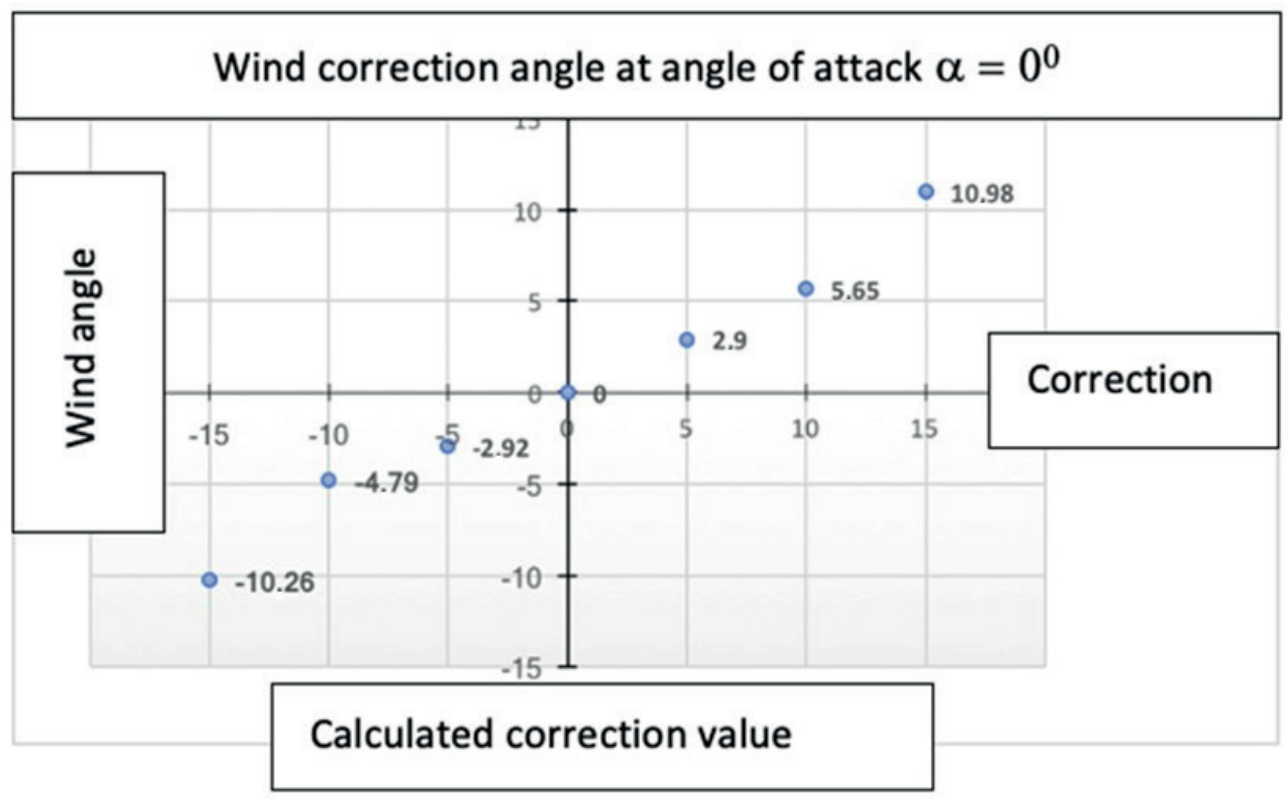

Figure 5 Relationship between the wing angle and wind correction angle at angle of attack $\alpha=0^{\circ}$ for the 1:19 scale F16 model 


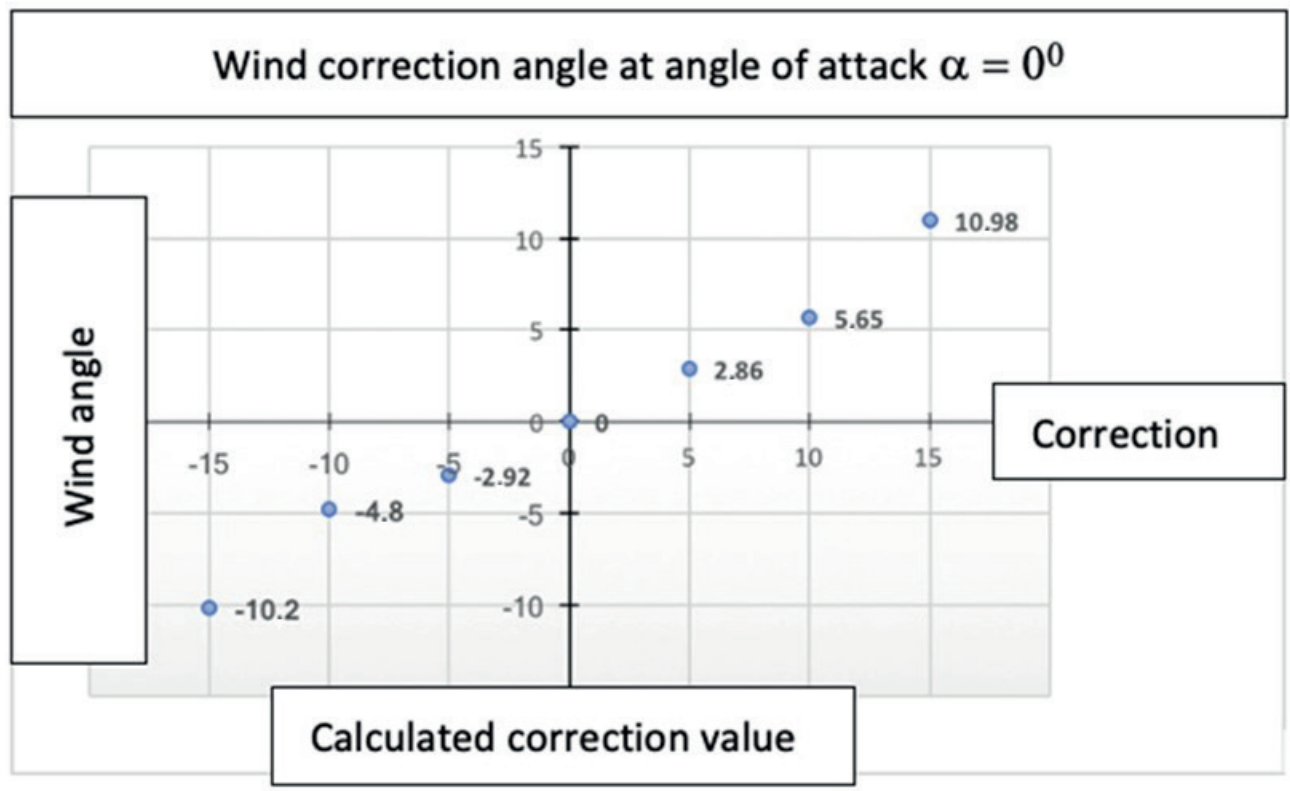

Figure 6 Relationship between the wind angle and wind correction angle at the angle of attack $\alpha=0^{\circ}$ for the full-scale F16 aircraft

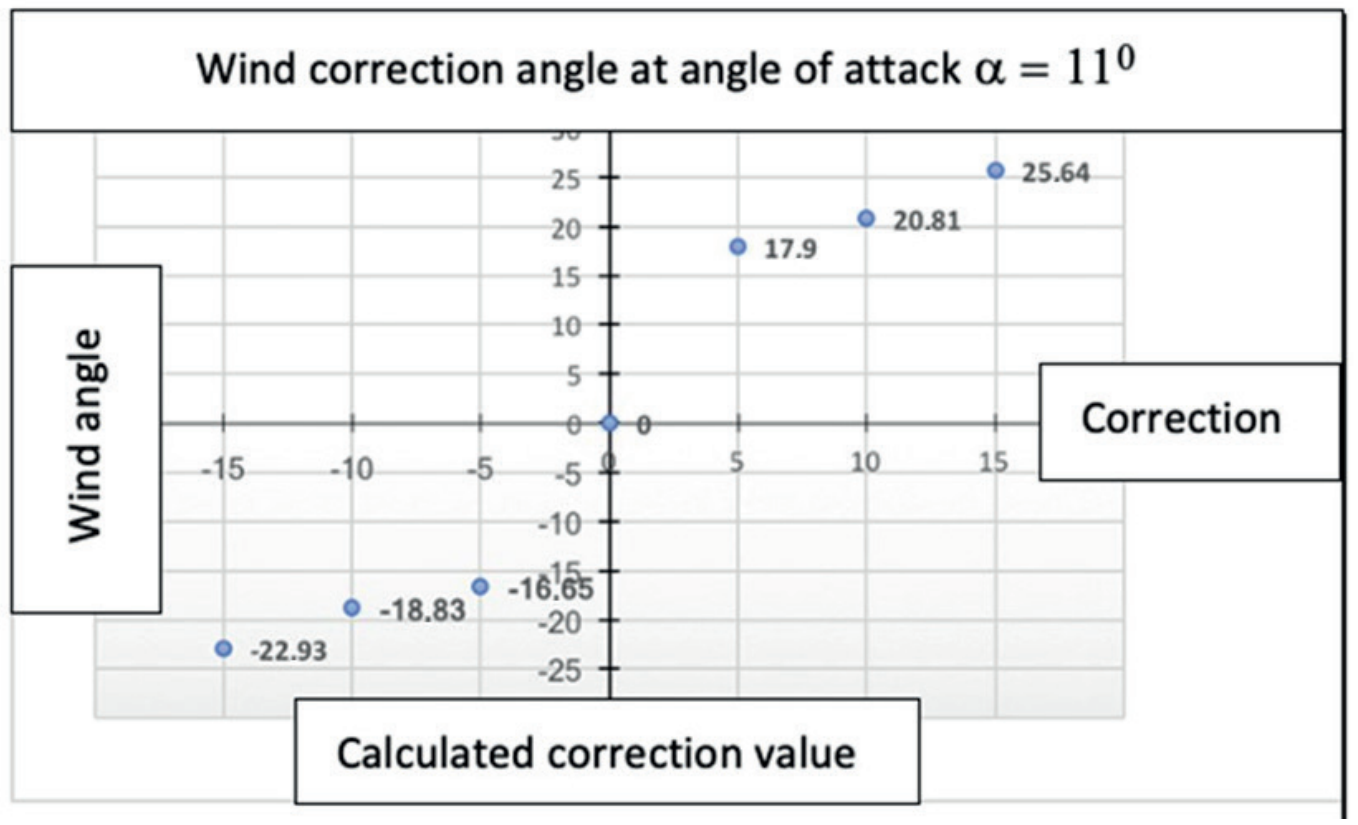

Figure 7 Relationship between the wind angle and wind correction angle at the angle of attack $\alpha=11^{\circ}$ for the 1:19 scale F-16 model

aircraft model as compared to the full-scale aircraft.

Figures 7 and 8 show the corrections calculated for the angle of attack $\alpha=11^{0}$. In this case, it may be noted that the graph of the $1 / 19$ model runs below that of the full-scale F-16. This is caused by differences between the correction values being on average approximately $0.05^{0}$.

\section{Conclusions}

The presented work shows the importance of position prediction for the precise and safe execution of the landing approach. Owing to the use of trigonometric relationships, exact parameters of the aircraft tested - in this case the F-16 - fundamental laws of aerodynamics and very precise tunnel tests' results, it is possible to determine the exact correction value to be introduced so that the aircraft can keep its trajectory in the longitudinal axis of the runway on which the landing has been planned. The impact of the crosswind, depending on its speed and direction, can significantly affect the flight trajectory of an aircraft and that can be seen by analyzing the results of the tests. The largest correction possible to determine was as much as $31.51^{0}$, 


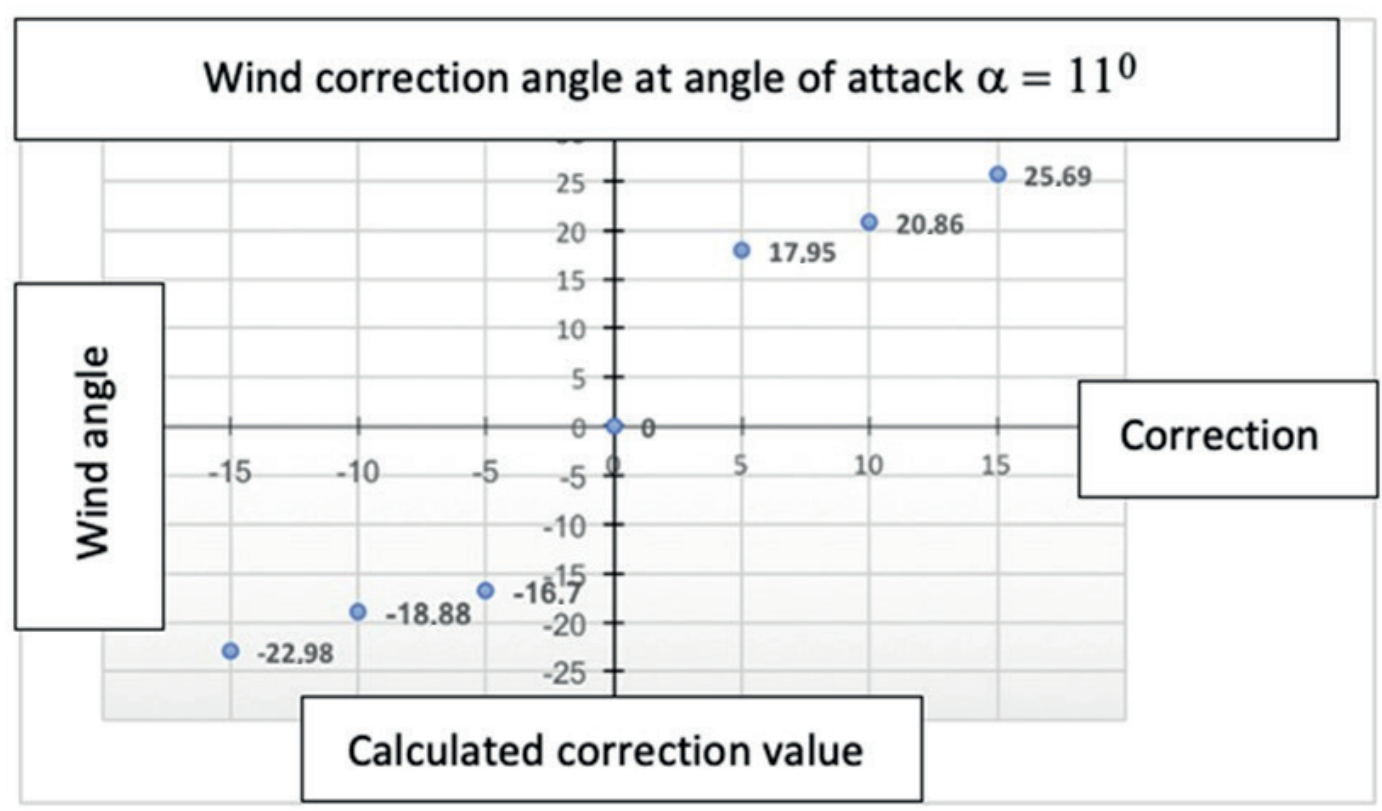

Figure 8 Relationship between the wind angle and wind correction angle at the angle of attack $\alpha=11^{\circ}$ for the full-scale $F$-16 aircraft

which shows how crosswind can influence the flight path, of e.g. an airplane. Such a large value of deviation constitutes a very significant change of direction. It should be remembered, however, that the calculations were performed for the wind speed reaching $40 \mathrm{~m} \cdot \mathrm{s}^{-1}$ at which in real life no air operation would be allowed to take place, as such conditions would not ensure the safety of flight operations.

\section{Acknowledgements}

This research was funded by Polish Air Force University Statutory Project: Prediction of Position on the Glide Path Using Bessel Equations - Testing the F16 Aircraft Drag Coefficient in the Function of Wind Angle, grant number PBN 03077/2017/WAT. The APC was funded by Polish Air Force University, Deblin Poland.

\section{References}

[1] ABLAMOWICZ, A., NOWAKOWSKI, W. Fundamentals of aerodynamics and flight mechanics / Podstawy aerodynamiki $i$ mechaniki lotu (in Polish). Warszawa: Wydawnictwa Komunikacji i Lacznosci, 1980. ISBN 83-206-0054-5, p. 25-26.

[2] GRZEGORZEWSKI, M. Navigating an Aircraft by Means of a Position Potential in Three-Dimensional Space / Nawigacja statku powietrznego za pomoca potencjalu pozycji w przestrzeni 3D (in Polish). Annual of Navigation. 2005, 9, p. 47-69. ISSN 1640-8632.

[3] LEITNER, R., ZAKOWSKI, W. Mathematics - preparatory course for technical universities / Matematyka - Kurs przygotowawczy na wyzsze uczelnie techniczne (in Polish). Warszawa: Wydawnictwa Naukowo-Techniczne, 1968. p. 421-431.

[4] LOCKHEED, M. US Air Force: F-16 C/D Block 50 and 52+ Supplemental Flight Manual. 1997. p. 144-146.

[5] FRANT, M., MAJCHER, M., RAPALA, E. Experimental studies in wind tunnel on drag coefficient as a function of sideslip angle / Doswiadczalne badania w tunelu aerodynamicznym wspolczynnika oporu czolowego modelu samolotu F-16 w funkcji kata slizgu (in Polish). Warszawa: Wojskowa Akademia Techniczna, 2017. p. 3-12.

[6] LOCKHEED, M. US Air Force: F-16 C/D Block 50 Flight Manual. 1996. p. 23, 212-215, 424. 